\title{
Bimodal silicone interpenetrating networks sequentially built as electroactive dielectric elastomers
}

\begin{tabular}{|r|l|}
\hline Journal: & Journal of Materials Chemistry C \\
\hline Manuscript ID: & TC-ART-05-2015-001391.R2 \\
\hline Article Type: & Paper \\
\hline Date Submitted by the Author: & n/a \\
\hline Complete List of Authors: & $\begin{array}{l}\text { Tugui, Codrin; "Petru Poni" Institute of Macromolecular Chemistry, } \\
\text { Inorganic Polymers } \\
\text { Stiubianu, George Theodor; "Petru Poni" Inatitute of Macromolecular } \\
\text { Chemistry, Inorganic Polymers } \\
\text { Iacob, Mihail; "Petru Poni" Institute of Macromolecular Chemistry, ; } \\
\text { Institute of Chemistry of ASM, } \\
\text { Ursu, Cristian; "Petru Poni" Institute of Macromolecular Chemistry, } \\
\text { Bele, Adrian; "Petru Poni" Institute of Macromolecular Chemistry, } \\
\text { Vlad, Stelian; "Petru Poni" Institute of Macromolecular Chemistry, } \\
\text { Cazacu, Maria; "Petru Poni" Institute of Macromolecular Chemistry, } \\
\text { Inorganic Polymers }\end{array}$ \\
\hline
\end{tabular}




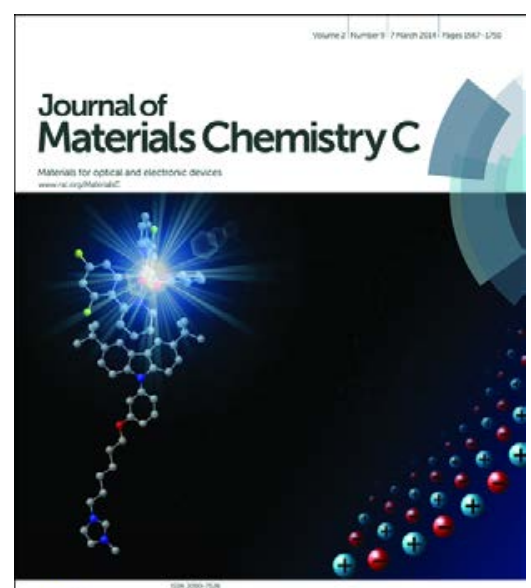

\section{Journal of Materials Chemistry C} Materials for Optical, Magnetic and Electronic Devices

\section{Full paper submission}

Journal of Materials Chemistry $C$ is a weekly journal in the materials field. The journal is interdisciplinary, publishing work of international significance on all aspects of materials chemistry related to optical, magnetic and electronic devices. Articles cover the fabrication, properties and applications of materials.

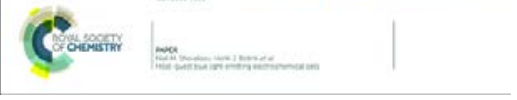

2013 Impact Factor of Journal of Materials Chemistry: $\mathbf{6 . 6 2 6}$

For more information go to www.rsc.org/materialsC

The following paper has been submitted to Journal of Materials Chemistry $C$ for consideration as a full paper.

Journal of Materials Chemistry $C$ wishes to publish original research that demonstrates novelty and advance, either in the chemistry used to produce materials or in the properties/applications of the materials produced. Work submitted that is outside of these criteria will not usually be considered for publication. The materials should also be related to the theme of materials for optics, magnetics and electronics.

Routine or incremental work, however competently researched and reported, should not be recommended for publication if it does not meet our expectations with regard to novelty and impact.

It is the responsibility of authors to provide fully convincing evidence for the homogeneity and identity of all compounds they claim as new. Evidence of both purity and identity is required to establish that the properties and constants reported are those of the compound with the new structure claimed.

Thank you for your effort in reviewing this submission. It is only through the continued service of referees that we can maintain both the high quality of the publication and the rapid response times to authors. We would greatly appreciate if you could review this paper in two weeks. Please let us know if that will not be possible.

Once again, we appreciate your time in serving as a reviewer. To acknowledge this, the Royal Society of Chemistry offers a $\mathbf{2 5 \%}$ discount on its books: http://www.rsc.org/Shop/books/discounts.asp. Please also consider submitting your next manuscript to Journal of Materials Chemistry $C$.

Best wishes,

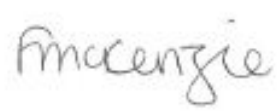

Dr Fiona McKenzie

Executive Editor, Journal of Materials Chemistry C 


\section{Bimodal silicone interpenetrating networks sequentially built as electroactive dielectric elastomers}

C. Tugui, G. Stiubianu, M. lacob, C. Ursu, A. Bele, S. Vlad and M. Cazacu

Dielectric elastomers with reasonable electromechanical performances are obtained by only choosing suitable siloxane precursors and construction mode of the IPN's on their basis. Due to full silicone nature without the involvement of polar components, the appearance of inhomogeneities due to agglomerations or phase separation is avoided.

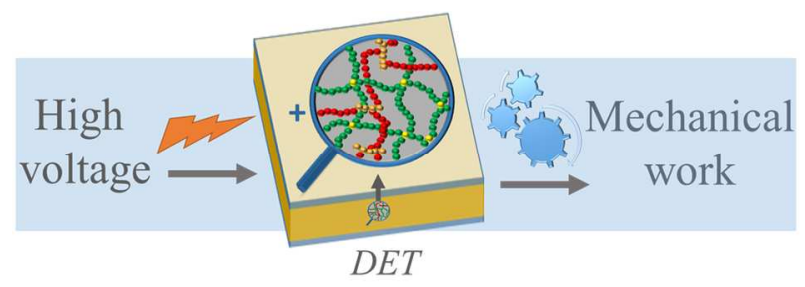




\title{
Journal Name
}

\section{ARTICLE}

\section{Bimodal silicone interpenetrating networks sequentially built as electroactive dielectric elastomers}

Received 00th January 20xx,

Accepted 00th January 20xx

DOI: $10.1039 / \times 0 \times x 00000 x$

www.rsc.org/

\author{
C. Tugui, G. Stiubianu, M. lacob, C. Ursu, A. Bele, S. Vlad and M. Cazacu
}

Two polysiloxanes, a polydimethylsiloxane- $\alpha, \omega$-diol (PDMS) with $M_{n}=370000 \quad \mathrm{~g} \cdot \mathrm{mol}^{-1}$, and $\alpha, \omega$ bis(vinyl)polydimethylsiloxane (Vi 2 PDMS) with $M_{n}=34500 \mathrm{~g} \cdot \mathrm{mol}^{-1}$, and proper crosslinking systems for each of them (tetraethyl orthosilicate - dibutyltindilaurate and $\alpha, \omega$-bis(trimethylsiloxy)poly(dimethylmethyl-H-siloxane) - Speier's catalyst, respectively), were mixed together in various weight ratios (1:0.1, 1:0.2, 1:0.3, 1:0.5) and cast in films. These were sequentially crosslinked by different mechanisms from each other. A determined pre-stretch was applied to the first network after its formation followed by the thermal treatment for the curing the second network. Non-prestreched networks were also prepared in parallel for comparison. The aged films were characterized from the point of view of the soluble fraction content, and analysed by differential scanning calorimetry, water vapour sorption in dynamic regime, dielectric spectroscopy and tensile tests. Dielectric strength and actuation strain were measured to estimate the suitability of the samples for electromechanical applications. The results revealed that through this approach can be relatively easily obtained very simple and homogeneous materials suitable for use as dielectric elastomer transducers.

Silicones and especially polydimethylsiloxanes (PDMSs) often attracted high interest for practical applications due to their extremely interesting properties that are stable over a wide range of temperature, moisture or frequency. ${ }^{1}$ Lately, mainly due to high flexibility regardless of temperature, silicones were approached as dielectric elastomers for electromechanical applications $^{2-4}$, where it should meet certain conditions, such as high stability, small mechanical hysteresis, high elasticity, high dielectric permittivity, high breakdown strength, easy film-formation, etc. Of these, dielectric permittivity is a weakness for silicones. Still looking for ways to improve this feature, the incorporation of the adequate fillers ${ }^{5-7}$ and chemical modification of the polymeric matrix by attaching polar groups ${ }^{8-10}$ are the most popular. The use of copolymers, ${ }^{11-13}$ blends, ${ }^{14,15}$ and interpenetrating polymer networks have also been considered as alternatives to optimize the electromechanical properties of the silicones. ${ }^{16-19}$ But besides the expected improvements, some difficulties are encountered to each approaches mentioned, mainly related to decreasing of dielectric strength or the homogeneity of the resulted system, such as: agglomeration of the filler particles and their low compatibility with the polymeric matrix, phase separation of the network components. Silicones, and particularly PDMSs, are known for their incompatibility with

\footnotetext{
a. "Petru Poni" Institute of Macromolecular Chemistry, Iasi, 700487, Romania; mcazacu@icmpp.ro.

†Electronic Supplementary Information (ESI) available: DSC traces for prepared IPNs, The main parameters of DSC curves, Sorption-desorption isotherms registered in dynamic regime at room temperature for IPNs as compared with references Net1 and Net1. See DOI: 10.1039/x0xx00000x
}

the most of organic and inorganic partners. ${ }^{20,8}$ So often the increase of the dielectric constant is obtained by sacrificing other properties, especially those mechanical. Some recent approaches in terms of dielectric elastomers refers to the bimodal PDMS/PDMS interpenetrating networks built on two precursor polymers with different molecular masses and having the same or different functionalities. According to the latter, the formation of interpenetrating polymer network (IPN) will occur simultaneously (the crosslinking of the two polymers through a single crosslinker through the same mechanism ${ }^{21,22}$ ) or sequentially (the polymers having different functional groups are each reacted with proper multifunctional cross-linking agents by separate mechanisms ${ }^{23}$ ). The effect of bimodality of the constituent silicone chains on the mechanical properties of silicone networks has been a subject of extensive studies, the comparison of networks generated simultaneously or sequentially being of great theoretical interest. ${ }^{24}$ Some of the more recent reviews summarise the findings. ${ }^{25,26}$ Silicones have served as model elastomeric networks, their systematic studies contributing to the development of rubber elasticity theories. ${ }^{25-27}$ The availability of a wide variety of functional silicones and cure chemistries offers large opportunities for this. $^{28}$

In general, the studies reported in the literature related to bimodal silicone networks are made on polydimethylsiloxanes pairs with different low molecular weights, i.e., 450 and 21000 $\mathrm{g} \cdot \mathrm{mol}^{-1}, 2910500$ and $28000 \mathrm{~g} \cdot \mathrm{mol}^{-1}, 22,13000$ and $75000 \mathrm{~g} \cdot \mathrm{mol}$ ${ }^{1}, 3088000 \mathrm{~g} \cdot \mathrm{mol}^{-1}$ and $100 \mathrm{mPa} \cdot \mathrm{s}^{31}$ or commercial silicone kits without specifying the molecular weights of polymers. ${ }^{31-33}$ 
The study on simultaneous bimodal networks permitted the conclusion that the network based on long chain prepolymers provides high tear energy, while that based on short chains with high crosslinking density support most of applied stress making less visible the imperfections obviously present in monomodal networks. Thus, it was proved that the tensile and shear properties could be improved by bimodality of the silicone networks. ${ }^{31,34}$

Pei et al reported the obtaining of better and softer materials by blocking the elastomer films in prestrain state through the sequential interpenetration of two commercial silicone kits: one consisting in a soft silicone vulcanized at room temperature (RTV) which acts as host network and the other, in a more rigid one cured at elevated temperature (HTV), as a guest network. ${ }^{33}$ By blocking the softer polymeric films (RTV) in prestrain state was demonstrated that the electromechanical instability diminishes and also the stressstrain plateau is inhibited. ${ }^{18,35}$

By using the Pei's procedure, we prepared a series of bimodal siloxane interpenetrating networks (IPNs) by using two common silicone polymers with high molecular weights (34500 and $370000 \mathrm{~g} \cdot \mathrm{mol}^{-1}$ ) and with a large difference between them values. These were mixed in different weight ratios and sequentially crosslinked by different mechanisms from each other. A pre-stretch was applied to the host network after its formation followed by the thermal treatment for the curing the second network. The resulted IPNs were characterized in terms of the soluble fraction content, as well as thermal, mechanical, and dielectric properties and were submitted to actuation tests to evaluate their suitability for use as dielectric elastomer transducers. While the Pei's results highlighted the influence of the locked prestrain on the electromechanical behavior, our work aims also to evaluate the importance of network's bimodality in the tuning of the actuation performances.

\section{Results and discussion}

A polydimethylsiloxane- $\alpha, \omega$-diol (PDMS) having an average numerical molecular weight, $M_{n}$, of $370000 \mathrm{~g} \cdot \mathrm{mol}^{-1}$ and a $\alpha, \omega$ bis(vinyl)-polydimethylsiloxane ( $\left.\mathrm{Vi}_{2} \mathrm{PDMS}\right)$ with a molecular mass of about 10 times smaller $\left(M_{n}=34500 \mathrm{~g} \cdot \mathrm{mol}^{-1}\right)$ as precursors for the networks Net1 and Net2, respectively, were used to prepare IPNs (Figure 1) by a procedure similar to that reported by Pei et al. ${ }^{33}$ which used commercial silicone kits. The two polymers were mixed in different ratios in solutions of high concentrations in toluene, poured into film moulds and subsequently cured to form free standing films. The curing of the two polymers occurred by distinct mechanisms, first by condensation at room temperature with tetraethylortosilicate in presence of DBTDL, when the high molecular weight PDMS$\alpha, \omega$-diol is converted into network hosting the still raw precursors of the second network. The latter was subsequently cured by hydrosilylation with a $\alpha, \omega$-bis(trimethylsiloxy)poly(dimethylmethyl-H-siloxane) PDMMHS with low molecular weight $\left(M_{n}=4200 \mathrm{~g} \cdot \mathrm{mol}^{-1}\right)$ as a crosslinking agent, in presence of Speier's catalyst. The full silicone nature, mixing the two polymers in raw state, and their crosslinking by different mechanisms create the prerequisites for the formation of IPNs.

(I)

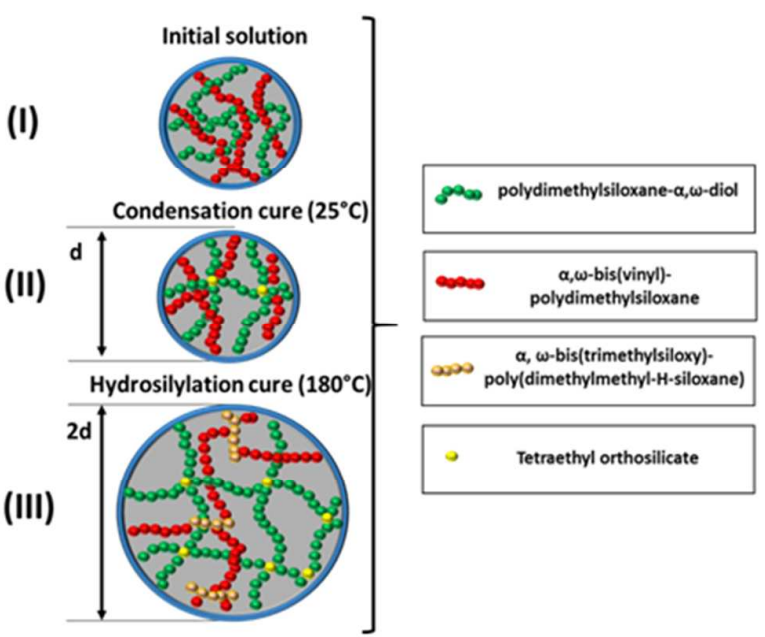

Figure 1. Schematic protocol to prepare stretched IPNs adapted from ref. ${ }^{33}$ : I - initial solution containing the two IPNs precursors; II - curing first network through a condensation mechanism at room temperature and the solvent evaporation; III - curing through a hydrosilylation reaction at elevated temperature of the second network interpenetrated with the stretched first one.

After stabilizing the first network through condensation at room temperature, the films were detached from the substrate, $100 \%$ equibiaxially stretched and submitted to the conditions for the formation of the second network $\left(180^{\circ} \mathrm{C}\right)$. Due to the rigid nature of the Net2 network, after removing the initial stretching, the films did not return to its original shape keeping a part of initial strain. ${ }^{33}$ From the equation that describes the actuation mode $p=\varepsilon \varepsilon_{0} E^{2}$, it follows that the electrostatic pressure between electrodes is directly proportional to the square of the applied electric field, therefore the displacement is limited by the breakdown strength. It was found that prestrain prevents the electromechanical instability shortening or eliminating stressstrain high plateau typical for most soft elastomers ${ }^{36}$ and leads to increases in breakdown voltage. ${ }^{35,37}$. On the other hand, due to the bimodal nature, the incidence of chain irregularities (i.e. the presence of free polymer ends) more exposed in monomodal networks is diminished, which should lead to the reduction or suppresion of electromechanical instability ${ }^{38,39}$.

A series of samples differing by the content of the denser network Net2 $(10,20,30,50$ wt\% reported to first one) were prepared, characterized and analysed by different techniques for a preliminary evaluation of their suitability for application in electromechanical devices.

After curing and aging, the amount of prestrain preserved was assessed by physical measurements and reporting the final dimension (free standing film) to the original size (before prestretching). As it can be seen in Figure 2, the amount of retained prestrain increases by increasing the Net2 content in IPN. This increase may be explained by the greater rigidity of 
Table 1. Recipes used to prepare networks

\begin{tabular}{|c|c|c|c|c|c|c|}
\hline Sample & $\begin{array}{l}\text { Precursors for } \\
\text { network } 1^{\text {a }} \\
\text { (PDMS/TEOS) } \\
\mathrm{g} / \mathrm{ml}\end{array}$ & $\begin{array}{l}\text { Precursors for } \\
\text { network } 2^{b} \\
\text { (Vi }_{2} \text { PDMS / } \\
\text { PDMMHS) } \\
\mathrm{g} / \mathrm{g}\end{array}$ & $\begin{array}{l}\text { Percentage } \\
\text { Net2 toward } \\
\text { Net } 1 \text { in IPN, } \\
\text { wt\% }\end{array}$ & $\begin{array}{l}\text { Preparation } \\
\text { procedure }\end{array}$ & $\begin{array}{l}\text { Fraction } \\
\text { soluble in } \\
\text { toluene, } \\
\text { wt\% }^{c}\end{array}$ & $\begin{array}{l}\text { Moisture } \\
\text { sorption } \\
\text { capacity at } \\
\text { RH } 80 \%, \text { RT }\end{array}$ \\
\hline Net1 & $2 / 0.2$ & & - & Normal & 13.9 & 0.42 \\
\hline Net2 & - & $2.0625 / 0.2811$ & - & Normal & 4.3 & 0.35 \\
\hline IPN-10 & $2 / 0.2$ & $0.2064 / 0.0280$ & 10 & Normal & 8.7 & 0.37 \\
\hline IPN-10p & $2 / 0.2$ & $0.2064 / 0.0280$ & 10 & Prestrained & 7.6 & 0.35 \\
\hline IPN-20 & $2 / 0.2$ & $0.4124 / 0.0562$ & 20 & Normal & 13.3 & 0.26 \\
\hline IPN-20p & $2 / 0.2$ & $0.4124 / 0.0562$ & 20 & Prestrained & 14.2 & 0.26 \\
\hline IPN-30 & $2 / 0.2$ & $0.6186 / 0.0843$ & 30 & Normal & 13.3 & 0.41 \\
\hline IPN-30p & $2 / 0.2$ & $0.6186 / 0.0843$ & 30 & Prestrained & 12.7 & 0.43 \\
\hline IPN-50 & $2 / 0.2$ & $1.0312 / 0.1405$ & 50 & Normal & 6.4 & 0.39 \\
\hline IPN-50p & $2 / 0.2$ & $1.0312 / 0.1405$ & 50 & Prestrained & 9.9 & 0.37 \\
\hline
\end{tabular}

${ }^{\mathrm{a}} 0.01 \mathrm{ml} \mathrm{DBTDL} ;{ }^{\mathrm{b}} 0.01 \mathrm{ml}$ Speier`s catalyst; ${ }^{\mathrm{c}}$ soluble fraction extracted after $48 \mathrm{~h}$ immersion in toluene with continue shaking.

the second network formed after the first network was stretched thereby restricting its return to original size, the more so as it is in larger quantities. The soluble fraction of each IPN was estimated. For this, the aged IPNs were extracted in toluene for 48 hours and the obtained results are presented in Table 1. It can be seen that, the soluble fraction of Net1 is 13.9 wt\%, while Net2 had the smallest soluble fraction, i.e., 4.3 wt\%, This difference is expected one taking into account the crosslinking patterns of the two networks. Thus, while the second network is formed by dense bridges generated between short chains $\left(\mathrm{Mn}=34500 \mathrm{~g} \cdot \mathrm{mol}^{-1}\right)$ by hydrosilylation, the first network is crosslinked through ends of very long chains $\left(\mathrm{Mn}=370000 \mathrm{~g} \cdot \mathrm{mol}^{-1}\right)$, existing a higher probability for some chains to remain free and, due to their high molecular mass, the contribution to the soluble fraction is significantly.

On the DSC curves registered in the range $-150 \div+50{ }^{\circ} \mathrm{C}$ (Figure S1) there are present the peaks corresponding to all thermal transitions (glass transition, crystallization, melting), which are those characteristic for silicones and not are affected in a fundamental way by the ratio between the two networks or by prestrain.

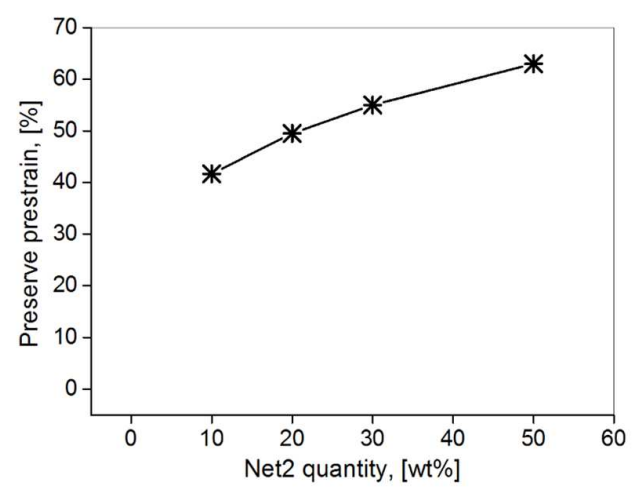

Figure 2. Amount of preserved prestrain in dependence on the wt\% content of Net2 in IPN.
As expected, due to their full silicone nature, the samples behave in humid atmosphere as hydrophobic ones as sorptiondesorption isotherms show (Figure S2). The moisture sorption values registered at $80 \%$ humidity are all in the range 0.26 0.43 wt\% (Table 1). Neither the composition nor unstretched or pre-stretched states does not affect systematically and significantly the moisture behaviour. These low values constitute a guarantee for stability of the material in wet fluctuating conditions.

In order to establish the mechanical behaviour of the freestanding aged IPNs films, mechanical tests were performed both in normal and cyclic regime (Figure 3 ). The normal stressstrain curves show that the break elongation values of IPNs are intermediate between those of pure networks, Net1 and Net2, of 1031 and $279 \%$, respectively (Table 2 ).
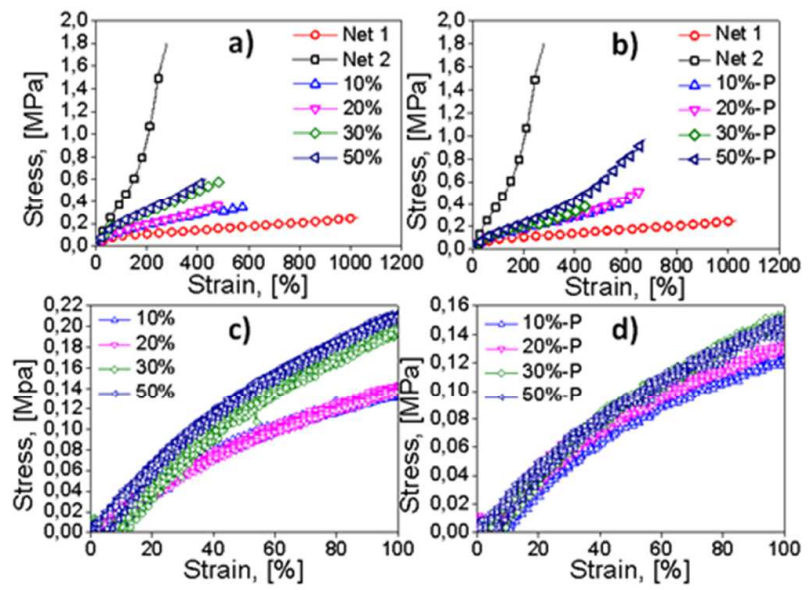

Figure 3. Stress-strain curves in normal (top) and cyclic (bottom) regime for: unstretched $(a, c)$ and pre-stretched $(b, d)$ samples. 
Table 2. The main mechanical and dielectric characteristics of IPNs at $25^{\circ} \mathrm{C}$.

\begin{tabular}{|c|c|c|c|c|c|c|c|c|}
\hline Sample & Thickness, $\mu \mathrm{m}$ & $\begin{array}{l}\text { Young } \\
\text { modulus, }^{\text {a }} \\
\mathrm{MPa}\end{array}$ & $\begin{array}{l}\text { Elongation at } \\
\text { break, } \varepsilon, \%\end{array}$ & $\varepsilon^{\prime}$ at $1 \mathrm{~Hz}$ & $\begin{array}{l}\varepsilon^{\prime} \text { at } 10^{4} \\
\mathrm{~Hz}\end{array}$ & $\varepsilon^{\prime \prime}$ at $1 \mathrm{~Hz}$ & $\begin{array}{l}\varepsilon^{\prime \prime} \text { at } 10^{4} \\
\mathrm{~Hz} \\
\cdot 10^{-3}\end{array}$ & $\begin{array}{l}\text { Ebd, }^{b} \\
M V / m\end{array}$ \\
\hline Net1 & 100 & 0.12 & 1031 & 3.6 & 3.6 & 0.7 & 2.3 & 35.5 \\
\hline Net2 & 300 & 0.57 & 279 & 7.8 & 3.3 & 20.1 & 1.0 & 45.6 \\
\hline IPN-10 & 210 & 0.13 & 587 & 3.3 & 3.2 & 1.5 & 2.1 & 38.0 \\
\hline IPN-10p & 110 & 0.13 & 623 & 3.2 & 3.0 & 2.2 & 1.5 & 39.0 \\
\hline IPN-20 & 180 & 0.26 & 484 & 2.8 & 2.7 & 3.2 & 3.5 & 42.4 \\
\hline IPN-20p & 85 & 0.24 & 668 & 3.2 & 2.8 & 5.0 & 3.1 & 56.4 \\
\hline IPN-30 & 130 & 0.28 & 484 & 3.0 & 2.8 & 3.1 & 1.6 & 47.3 \\
\hline IPN-30p & 100 & 0.25 & 448 & 2.9 & 2.8 & 3.8 & 2.1 & 59.9 \\
\hline IPN-50 & 210 & 0.35 & 433 & 3.2 & 3.0 & 18.7 & 3.0 & 48.0 \\
\hline IPN-50p & 75 & 0.27 & 674 & 3.6 & 3.3 & 5.4 & 1.0 & 64.0 \\
\hline
\end{tabular}

determined at $10 \%$ strain;

belectric breakdown field.

By comparing the two pure networks with derived IPNs, an increasing in Young modulus values occurs by incorporating the second network within the first one, from $0.12 \mathrm{MPa}$ for pure Net1 to $0.35 \mathrm{MPa}$ for IPN-50 (Table 2). Instead, the prestretched samples show slightly lower values of the Young modulus as compared with unstretched ones, as less as the content of the Net2 increases (i.e., from 0.26 to 0.24 , from 0.28 to 0.25 , and from 0.35 to $0.27 \mathrm{MPa}$, in the cases of the pairs IPN-20 and IPN-20p, IPN-30 and IPN-30p, IPN-50 and IPN50-p, respectively). The cyclic stress-strain curves (Figure $3 c, d)$ show a very small hysteresis suggesting only a small plastic deformation. The amount of energy per volume that the material can absorb during its stretching was estimated as area under tensile stress-strain curves for the elastic plateau ${ }^{40-}$ 42. This is assimilated to the elastic energy density which is usually a measure to compare different actuator materials. As can be seen from Table 3, the value of this characteristic increases as the IPN is richer in densely crosslinked component, Net2 (with $0.201 \mathrm{~J} / \mathrm{cm}^{3}$ ), from $0.002 \mathrm{~J} / \mathrm{cm}^{3}$ for pure Net1 to $0.081 \mathrm{~J} / \mathrm{cm}^{3}$ for IPN-50.
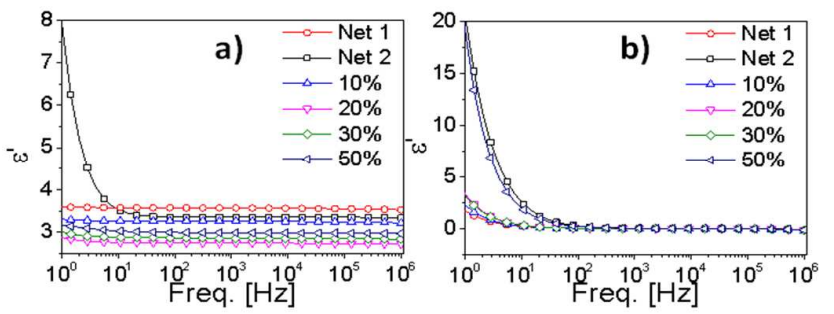

Figure 4. Dielectric spectra of unstretched films: a) dielectric permittivity and b) dielectric losses.

Dielectric spectroscopy results indicate no significant differences neither between samples with different compositions (Figure 4) nor between their unstretched and pre-stretched states in which case the curves practically overlap. Moreover, all samples show a dielectric behaviour typical for silicones having an almost constant permittivity, $\varepsilon^{\prime}$ around 3, over entire range of frequency excepting Net2 sample, which showed a sharp increase at low frequencies ranging from $\varepsilon^{\prime}=3.3$ at $10 \mathrm{~Hz}$ to $\varepsilon^{\prime}=7.8$ at $1 \mathrm{~Hz}$ (Table 2). The higher dielectric permittivity in the case of sample Net2 as compared with that of Net1 could be due to at least two causes: (i) the presence of $\mathrm{Pt}(0)$ colloids in situ formed in Net2 by reduction of hydrosilylation catalyst ((IV) hexachloroplatinic acid $)^{43}$ that remains in the sample after fulfilling its mission, as has been proven by energy-dispersive $\mathrm{X}$-ray (EDX) analysis (Figure S3), and (ii) polar $\mathrm{Si}-\mathrm{OH}$ groups, whose presence is manifested by specific absorption bands in FTIR spectrum of Net2 network (Figure S4) resulted from the hydrolysis of possible residual $\mathrm{Si}-\mathrm{H}$ groups non-involved in hydrosilylation reaction. To them, it would add the decreasing of the free volume as a result of its higher crosslinking density. By denser crosslinking, the chain become more packed thus reducing configurational free volume. ${ }^{44}$ The dielectric loss values are in general low, excepting samples Net2 and the IPN-50 with the highest content of Net2 (and implicitly being expected to have the highest content of catalyst and $\mathrm{OH}$ groups and the highest density of crosslinking), which at $1 \mathrm{~Hz}$ show loss values of 20.1 and 18.7. The ratio between the dielectric loss and dielectric permittivity quantified as $\tan \delta$, roughly increases by the content of Net2, while at higher frequencies, this is very low in all cases being difficult to identify a trend (Table S2).

The electric breakdown field (EBD) or dielectric strength defined as the maximum voltage required to produce a dielectric breakdown through the material, was determined for all samples (Table 2). The measurements were made in environmental temperature and humidity conditions, in actuation mode by applying a ramp signal of $500 \mathrm{~V} / \mathrm{s}$ between two unequal planar circular electrodes arranged coaxially with a roughness of $3 \mathrm{~nm}$.

Because the thickness of an insulating material plays a role in determining its breakdown voltage, this is expressed in $\mathrm{MV} / \mathrm{m}$ for rough estimation and comparison of the results on the 
samples with different thicknesses, although the relationship between breakdown voltage and thickness is not exactly linear. As expected, our results (Table 2, Figure 5) indicate that the breakdown voltage values for pre-stretched films are greater than unstretched ones in all cases. Furthermore, the breakdown voltage value increases with increasing the concentration of Net2 precursor in IPN matrix, from $E_{B D}=39$ $\mathrm{MV} / \mathrm{m}$ for IPN-10p to $E_{B D}=64 \mathrm{MV} / \mathrm{m}$ for sample IPN-50p.

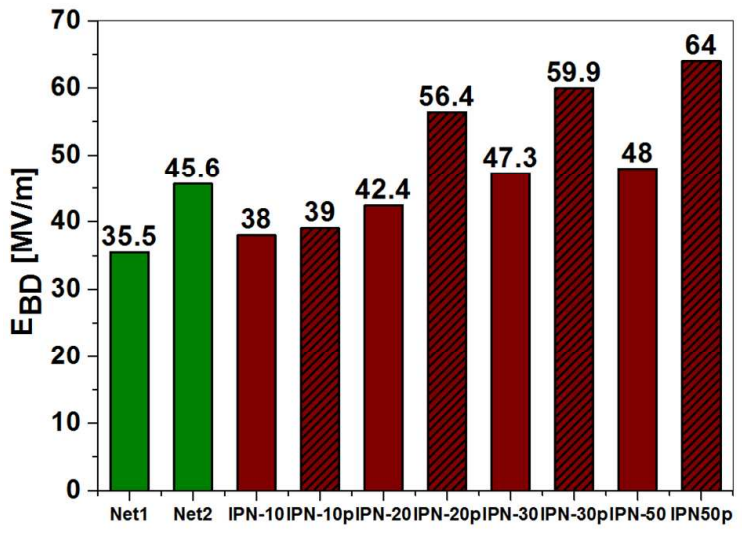

Figure 5. Diagram showing comparative EBD values for samples with different compositions and in different states (unstretched or prestretched).

The electrostatic pressure which depends on the dielectric permittivity and breakdown voltage also increases with increasing Net2 content in IPN.

The actuation measurements performed on an in house-built set up are showed in Figure 6. The silicone films with different Net2 contents were stretched equi-biaxially around 100\% related to its original size and locked on a circular shape frame. Both film surfaces were coated with carbon-grease compliant electrodes having a circular shape with a diameter of $8 \mathrm{~mm}$. A high voltage (HV) amplifier Trek 20/20C-HS with a range between 0-20KV was used in DC as HV power supply and an AFG3000 wave form function generator was used to generate a symmetric rectangular signal with a frequency of $0.5 \mathrm{~Hz}$. The signal was shifted toward positive values by using an offset equal with rectangular signal amplitude. The applied voltage on the dielectric elastomer film was measured by using a HV probe connected to a digital oscilloscope. In order to perform

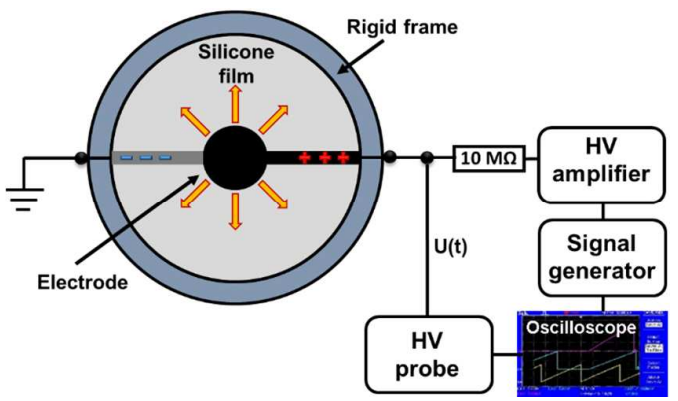

Figure 6. Schematic actuation measurements setup. the actuation measurements at the same electric field (around $40 \mathrm{KV} / \mu \mathrm{m})$, different voltages were required due to different samples thickness. The electrode surface displacement which occurs during actuation was measured by using a video camera. The determined values for actuation are provided in Table 3 and suggestive represented in Figure 7.

With respect to the obtained in-plane actuation strain values (Table 3), an increasing of their values was observed with growing the amount of Net2 content within IPN from $2.47 \%$ (IPN-10) to $7.90 \%$ (IPN-50). Withal, the same behaviour was observed in the case of pre-stretched samples, where the actuation strain range from $2.03 \%$ (IPN-10p) to $7.41 \%$ (IPN50p) but in this case the actuation values are each time slightly lower than the corresponding unstretched samples.

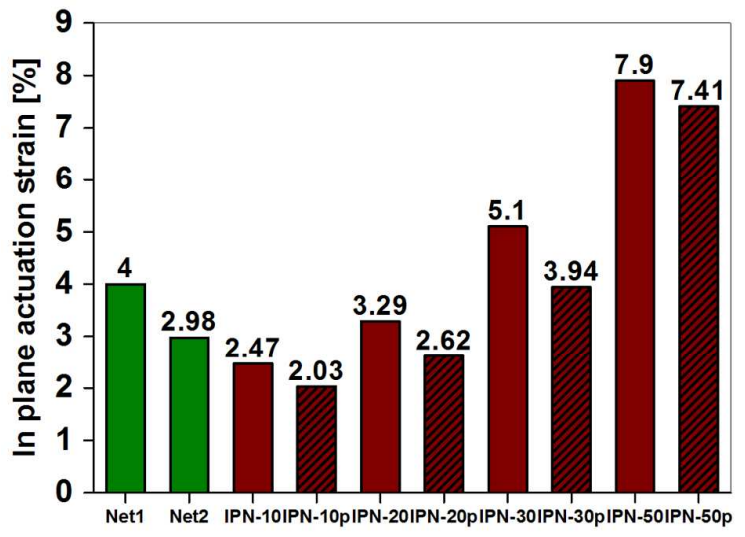

Figure 7. The diagram comparatively showing the in-plane actuation strain amounts.

The actuation strain in z direction (Sz), as is presented in Table 3 , increases in the same manner as in the case of in-plane strain by increasing the Net2 content, ranging between 2.41 for IPN-10 to $6.89 \%$ for Net-50p. It is noteworthy that the values of both in-plane and in $z$ direction actuation strains are slightly higher for the unstretched samples than for the prestretched ones.

The electromechanical sensitivity values (K') were obtained (Table 3 ) by reporting the actuation strain values in $z$ direction to the applied voltage. Another parameter, the coupling efficiency, $k^{2}$, which according to ref. ${ }^{45}$ is defined as electrical energy converted in mechanical work per cycle/electrical energy applied per cycle, was also calculated. Both parameters, $K^{\prime}$ and $k^{2}$, vary with the composition of the network and its status, similarly to the in-plane and in $z$ direction actuation strains.

An interesting observation is that, the actuation measured and $\mathrm{K}^{`}$ and $\mathrm{k}^{2}$ parameters determined for Net1 have higher values than those determined for Net2. By incorporating $10 \mathrm{wt} \%$ Net2 within Net1, the values of these parameters decrease even below those corresponding to Net2 and then to grow as the Net2 percentage added increases. This means that the interpenetration of the two networks has not strictly a cumulative effect on the characteristics of actuators. 
Table 3. The actuation data for the prepared networks.

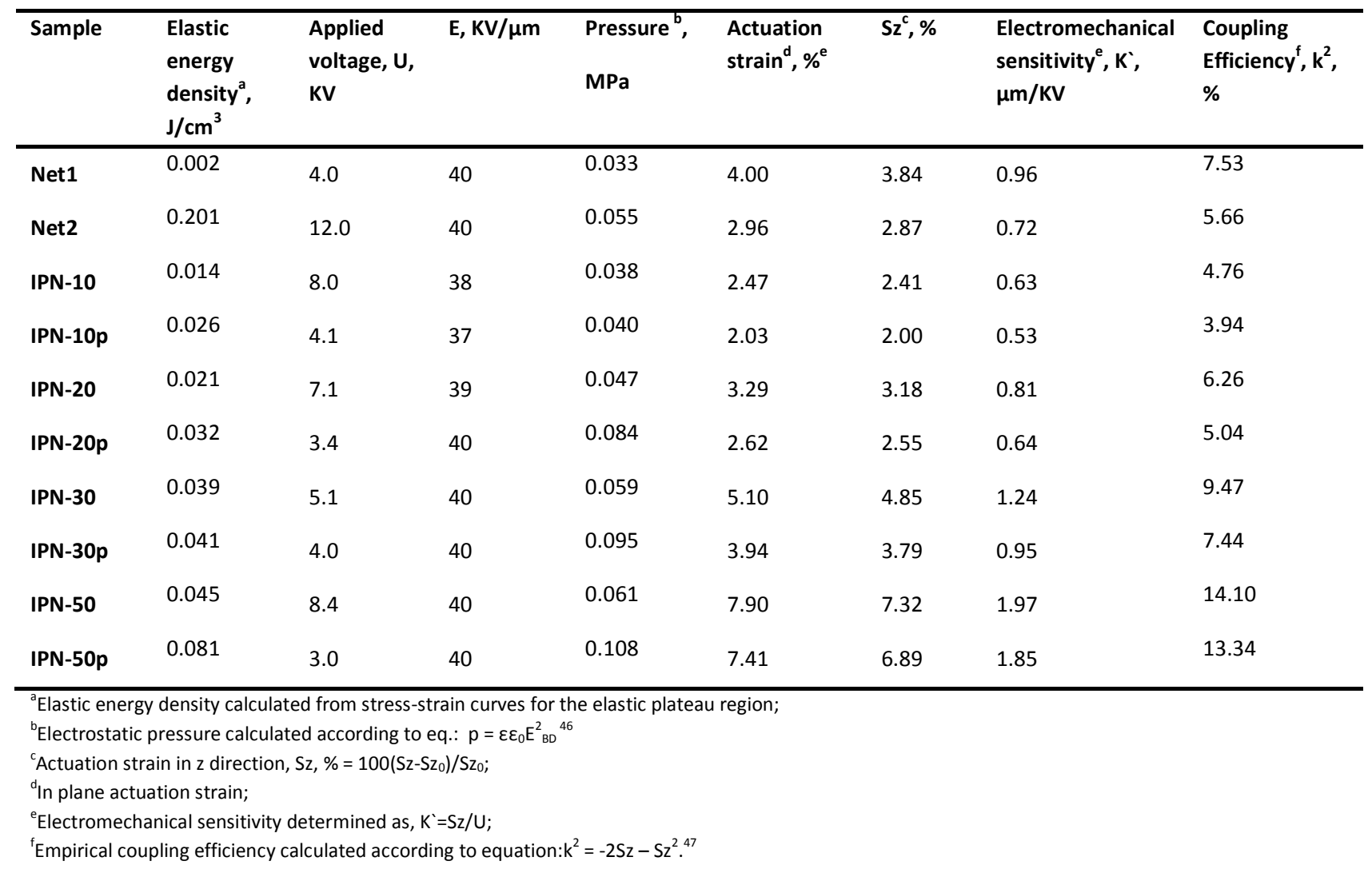

\section{Experimental}

\section{Materials}

Polydimethylsiloxane- $\alpha, \omega$-diol (PDMS) with $\mathrm{M}_{\mathrm{n}}=370000 \mathrm{~g} \cdot \mathrm{mol}^{-}$ ${ }^{1}$, as determinated by gel permeation chromatography (GPC), was prepared by cationic ring-opening polymerization of octamethylcyclotetrasiloxane $\left(D_{4}\right)$ catalysed by sulphuric acid, according to a previously described procedure. ${ }^{48} \alpha, \omega$ Bis(vinyl)polydimethylsiloxane, $\mathrm{Vi}_{2}$ PDMS, with a molecular weight $M_{n}=34500 \mathrm{~g} \cdot \mathrm{mol}^{-1}$ was synthesized by an equilibrium cationic ring-opening polymerization of $D_{4}$ in presence of 1,3bis(vinyl)tetramethyldisiloxane used to block the chains ends and provide vinyl terminal functionalities. ${ }^{49}$ The $\alpha, \omega$ bis(trimethylsiloxy)poly(dimethylmethyl-H-siloxane),

PDMMHS, with $\mathrm{M}_{\mathrm{n}}=4200 \mathrm{~g} \cdot \mathrm{mol}^{-1}$ with $22 \mathrm{~mol} \% \mathrm{Si}-\mathrm{H}$ groups was synthetized by equilibrium copolymerization of $D_{4}$ with $\alpha, \omega$ bis(trimethylsiloxy)poly(methyl-H-siloxane) homopolymer $\left(\mathrm{Mn}=2200 \mathrm{~g} \cdot \mathrm{mol}^{-1}\right.$, Fluka) in presence of Purolite CT-175. ${ }^{48}$ Dibutyltin dilaurate (DBTL), 95\%, and hexachloroplatinic(IV) acid hydrate, $\geq 99.9 \%$ trace metals basis, purchased from Sigma-Aldrich, Germany, and tetraethylorthosilicate (TEOS), 99.9\%, from Alfa Aesar, Germany were used as such.

\section{Equipments}

The molecular mass of the polymers was determined by gel permeation chromatography (GPC) in $\mathrm{CHCl}_{3}$ on a PL-EMD 950 chromatograph/evaporative mass detector instrument.

DSC 200 F3 Maia (Netzsch, Germany) was used for DSC measurements. About $10 \mathrm{mg}$ of sample was heated in pressed and punched aluminium crucibles at a heating rate of $10^{\circ} \mathrm{C} \cdot \mathrm{min}^{-1}$. A flow rate of $100 \mathrm{~mL} \cdot \mathrm{min}^{-1}$ of nitrogen was used as inert atmosphere.

TIRA test 2161 apparatus, Maschinenbau GmbH Ravenstein, Germany was used to perform the mechanical tests on dumbbell-shaped samples. The tests were done in normal condition at an extension rate of $20 \mathrm{~mm} \cdot \mathrm{min}^{-1}$. The fatigue resistance measurements were done by running five cycles with: stationary time at maximum strength $5 \mathrm{~s}$, stationary time at minimum strength $5 \mathrm{~s}$, maximum strain $100 \%$ and minimum strain $2 \%$.

Novocontrol setup (Broadband dielectric spectrometer Concept 40, GmbH Germany), integrating an ALPHA frequency response analyzer and a Quatro temperature control system, with working frequency range $10^{0}-10^{6} \mathrm{~Hz}$, at room temperature was used for the determination of the dielectric behavior. 
The breakdown voltage measurements were carried out in actuation mode on home-built setup (Figure 6). The experiments were performed by applying a ramp signal of 500 $\mathrm{V} \cdot \mathrm{s}^{-1}$ from a power generator with a range of $0 \div 20 \mathrm{kV}$ on the IPN samples which has been placed between two unequal planar electrodes with the edges rounded to give a radius of $0.5 \mathrm{~mm}$. The electrical voltage applied on the IPN membranes was measured by using a HV probe connected to a digital oscilloscope.

Water vapors sorption capacity of the film samples was measured by using the fully automated gravimetric analyzer IGAsorp supplied by Hiden Analytical, Warrington (UK). An ultrasensitive microbalance measuring the weight change as the humidity is modified in the sample chamber at a constant regulated temperature. The measurement system is controlled by a IGASORP Windows ${ }^{\mathrm{TM}}$ based software package.

\section{IPN films preparation}

$2 \mathrm{~g}$ of $\mathrm{OH}$-terminated PDMS was dissolved in $20 \mathrm{ml}$ toluene and then mixed with miscellaneous concentrations in second network precursor, Vi2PDMS, $10 \mathrm{wt} \%, 20 \mathrm{wt} \%, 30 \mathrm{wt} \%$ and 50 $w t \%$, respectively. After mixing the two polymers, $0.2 \mathrm{ml}$ TEOS and appropriate amount of PDMMHS as crosslikers, as well as $0.01 \mathrm{ml}$ DBTDL and $0.01 \mathrm{ml}$ Speier's (hexachloroplatinic(IV) acid as a 2 wt\% solution in isopropanol) as catalysts, were added to the polymers solution and well mixed again (Table 1 ). The solution was drop cast as thin films on a Teflon substrate frames and left for 48 hours at room temperature after that the formed films were peeled off from the substrate, $100 \%$ equibiaxially prestrained, and placed in an oven at $180{ }^{\circ} \mathrm{C}$ for $30 \mathrm{~min}$. After aging for two weeks under environmental conditions, the samples were analysed.

\section{Conclusions}

By building bimodal full silicone IPNs, reasonable electromechanical performances can be easily achieved without the involvement of polar components which induce the appearance of inhomogeneity due to agglomerations (for filler) or phase separation (in the case of polar groups or chain segments). Thus, starting from two home prepared polydimethylsiloxanes with a ratio between their molecular weights around 10 and differing by chain end functionalities and implicitly by crosslinking mechanism (one by condensation and the other by hydrosilylation), a series of IPNs were prepared by sequential procedure with or without prestretching the host network before curing the guest one. The results demonstrate that, except the dielectric permittivity and losses that are not changed significantly and in a systematic manner, other investigated properties (i.e., mechanical properties, breakdown voltage and actuation strain) are dependent on both composition of the network and the mode in which films were prepared (with or without pre-stretching host network). Thus, the increasing amount of the guest network, Net2 with a high crosslinking degree within the host
Net1, the Young modulus increases (e.g., from $0.12 \mathrm{MPa}$ for pure Net 1 to $0.35 \mathrm{MPa}$ by adding $50 \%$ Net2) while, in general elongation decreases as otherwise expected. Pre-stretching the host network partially counterbalance this trend having the opposite effect (module decreases and increases elongation). Thus, while the increasing Net2 content within IPN from 10 to $50 \%$ leads to an increase in linear strain actuation with $200 \%$, the $100 \%$ equibiaxially prestraining causes its decrease by $17.8,20.0,22.7,6.2 \%$ in the case of the four IPNs. These results allow to assess the importance of network's bimodality rather than of prestrain in the tuning of the actuation performances.

\section{Acknowledgements}

The work presented in this paper is developed in the context of the project PolyWEC (www.polywec.org, prj. ref. 309139), a FET-Energy project that is partially funded by the $7^{\text {th }}$ Framework Programme of European Community and cofinanced by Romanian National Authority for Scientific Research, CNCS-UEFISCDI (Contract 205EU). Thanks to Dr. Cristian Varganici for DSC measurements.

\section{Notes and references}

1 E. Formation, Macromolecules, 1993, 26, 5389-5395.

2 R. Loew and P. Meier, Finite Elem. Anal. Des., 2007, 43, 453462.

3 Silicon-Containing Polymers: The Science and Technology of Their Synthesis and Applications, Springer Science \& Business Media, 2001, vol. 30.

4 R. Pelrine, R. Kornbluh, Q. Pei and J. Joseph, Science (80-. )., 2000, 287, 836-839.

5 H. Liu, L. Zhang, D. Yang, Y. Yu, L. Yao and M. Tian, Soft Mater., 2013, 11, 363-370.

6 G. Gallone, F. Carpi, D. De Rossi, G. Levita and A. Marchetti, Mater. Sci. Eng. C, 2007, 27, 110-116.

7 M. Cazacu, M. Ignat, C. Racles, M. Cristea, V. Musteata, D. Ovezea and D. Lipcinski, J. Compos. Mater., 2013, 48, 15331545.

8 B. Kussmaul, S. Risse, G. Kofod, R. Waché, M. Wegener, D. N. McCarthy, H. Krüger and R. Gerhard, Adv. Funct. Mater., 2011, 21, 4589-4594.

9 A. L. Skov, S. Vudayagiri and M. Benslimane, in SPIE Smart Structures and Materials + Nondestructive Evaluation and Health Monitoring, ed. Y. Bar-Cohen, International Society for Optics and Photonics, 2013, p. 868711.

10 M. Cazacu and D. M. Opris, RSC Adv., 2014, 4, 37620-37628.

11 D. H. Kim, Z. Lin, H. C. Kim, U. Jeong and T. P. Russell, Adv. Mater., 2003, 15, 811-814.

12 T. Mirfakhrai, J. D. W. Madden and R. H. Baughman, Mater. Today, 2007, 10, 30-38.

13 H. Stoyanov, M. Kollosche, S. Risse, D. N. McCarthy and G. Kofod, Soft Matter, 2011, 7, 194-202.

14 F. Carpi, G. Gallone, F. Galantini and D. De Rossi, Adv. Funct. Mater., 2008, 18, 235-241.

15 G. Gallone, F. Galantini and F. Carpi, Polym. Int., 2010, 59, 400406. 
16 S. M. Ha, W. Yuan, Q. Pei, R. Pelrine and S. Stanford, Smart Mater. Struct., 2007, 16, S280-S287.

17 Z. Suo and J. Zhu, Appl. Phys. Lett., 2009, 95, 232909.

18 H. Zhang, L. Düring, G. Kovacs, W. Yuan, X. Niu and Q. Pei, Polym. Int., 2010, 59, 384-390.

19 L. H. Sterling, Encycl. Polym. Sci. Technol., 2004, 10, 272-311.

20 Y. S. Lipatov, Phase-Separated Interpenetrating Polymer Network, 2006.

21 A. G. Bejenariu, L. Yu and A. L. Skov, Soft Matter, 2012, 8, 3917.

22 F. B. Madsen, a E. Daugaard, C. Fleury, S. Hvilsted and a L. Skov, Rsc Adv., 2014, 4, 6939-6945.

23 J. E. M. Stephen J. Clarson, in Polymeric Materials Encyclopedia, ed. J. Salamone, USA, Boca Raton, Florida, Twelve Vol., 1996, pp. 7663-7677.

24 W. W. Wright, Br. Polym. J., 1987, 19, 228-228.

25 J. C. Salamone, Polymeric Materials Encyclopedia, CRC Press, Twelve Vol., 1996.

26 S. J. C. and J. E. Mark, in Siloxane polymers, ed. S. J. C. J. A. Semlyen, Englewood Cliffs, N.J. : Prentice Hall, 1993, p. 673.

27 D. R. Thomas, in Siloxane polymers, ed. S. J. C. J. A. Semlyen, Englewood Cliffs, N.J. : Prentice Hall, 1993, p. 673.

28 S. M. Ha, New Electroelastomers for High Performance Actuators, ProQuest, 2007, vol. 0.

29 J. E. Mark and Y.-P. Ning, Polym. Eng. Sci., 1985, 25, 824-827.

30 E. E. Hamurcu and B. M. Baysal, Polymer (Guildf)., 1993, 34, 5163-5167.

31 G. B. Shah, J. Appl. Polym. Sci., 2004, 94, 1719-1722.

32 L. Yu, L. B. Gonzalez, S. Hvilsted and A. L. Skov, 2014, 9056, 90560C.

33 P. Brochu, H. Stoyanov, X. Niu and Q. Pei, Smart Mater. Struct., 2013, 22, 055022.

34 J. W. and J. Mark, Polym. J., 1994, 26, 151-157.

35 S. M. Ha, W. Yuan, Q. Pei, R. Pelrine and S. Stanford, Adv. Mater., 2006, 18, 887-891.

36 P. Brochu and Q. Pei, Macromol. Rapid Commun., 2010, 31, 1036.

37 G. Kofod, R. D. Kornbluh, R. Pelrine and P. Sommer-Larsen, in SPIE's 8th Annual International Symposium on Smart Structures and Materials, ed. Y. Bar-Cohen, International Society for Optics and Photonics, 2001, pp. 141-147.

38 G. B. Shah, eXPRESS Polym. Lett., 2008, 2, 878-884.

39 C. M. Roland, in Encyclopedia of Polymeric Nanomaterials, eds. S. Kobayashi and K. Müllen, Springer-Verlag, Berlin Heidelberg, 2014, pp. 1-9.

40 M. A. Cole and C. N. Bowman, J. Polym. Sci. A. Polym. Chem., 2012, 50, 4325-4333.

41 C. P. Park, J. Polym. Eng., 2001, 21.

42 D. R. Askeland, P. P. Fulay and W. J. Wright, The Science and Engineering of Materials, Boston, USA, 7th edn., 2001.

43 G. J. J. Out, H.-A. Klok, L. Schwegler, H. Frey and M. Möller, Macromol. Chem. Phys., 1995, 196, 185-194.

44 G. Choudalakis and A. D. Gotsis, Curr. Opin. Colloid Interface Sci., 2012, 17, 132-140.

45 R. Pelrine, R. Kornbluh, J. Joseph, R. Heydt, Q. Pei and S. Chiba, Mater. Sci. Eng. C, 2000, 11, 89-100.

46 R. R. P. Kornbluh, Dielectric Elastomers as Electromechanical Transducers, Elsevier, 2008.

47 R. K. and R. Pelrine, in Dielectric Elastomers as Electromechanical Transducers, 2007, pp. 32-43.

48 M. Cazacu and M. Marcu, J. Macromol. Sci. Part A, 1995, 32, 1019-1029.
49 M. Cazacu, M. Marcu, A. Vlad, D. Caraiman and C. Racles, Eur. Polym. J., 1999, 35, 1629-1635. 


\section{Supporting information}

for Journal of Materials Chemistry C, See DOI: 10.1039/b000000x/

Bimodal silicone interpenetrating networks sequentially built as electroactive dielectric elastomers

C. Tugui, G. Stiubianu, M. Iacob, C. Ursu, A. Bele, S. Vlad and M. Cazacu
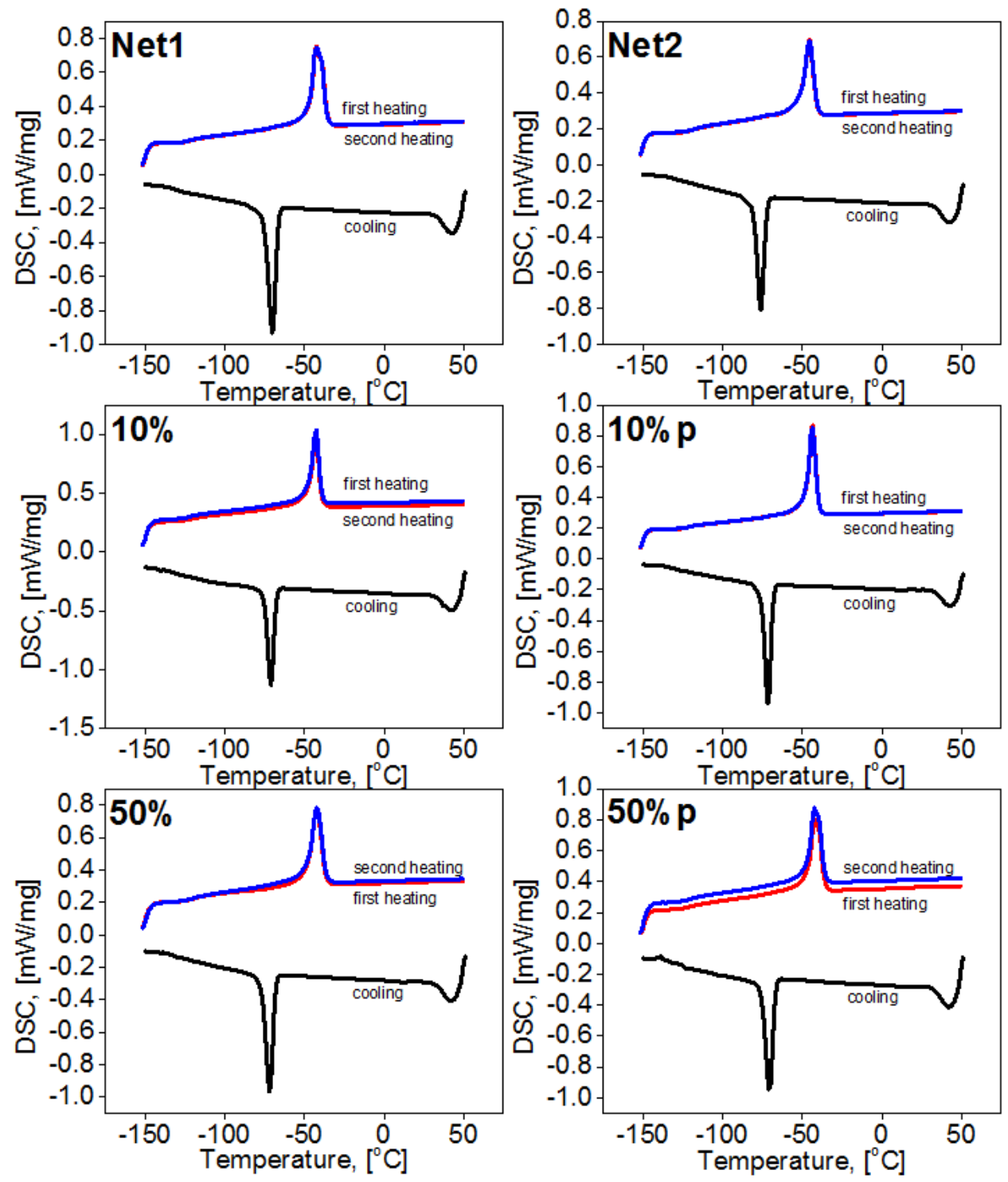

Figure S1. DSC traces for some of the prepared IPNs 
Table S1. The main parameters of DSC curves

\begin{tabular}{|c|c|c|c|c|c|c|c|c|c|c|}
\hline Sample & $\operatorname{Tg}_{\mathrm{h} 1}\left[{ }^{\circ} \mathrm{C}\right]$ & $\mathbf{T g}_{\mathrm{h} 2}\left[{ }^{\circ} \mathbf{C}\right]$ & $\begin{array}{l}\mathbf{T m}_{\mathrm{h} 1} \\
{\left[{ }^{\circ} \mathbf{C}\right]}\end{array}$ & $\begin{array}{l}\mathbf{T} \mathbf{m}_{\mathrm{h} 1} \\
{\left[{ }^{\circ} \mathbf{C}\right]}\end{array}$ & $\begin{array}{l}\mathbf{T} \mathbf{m}_{\mathrm{h} 2} \\
{\left[{ }^{\circ} \mathbf{C}\right]}\end{array}$ & $\begin{array}{l}\mathbf{T} \mathbf{m}_{\mathrm{h} 2} \\
{\left[{ }^{\circ} \mathrm{C}\right]}\end{array}$ & $\mathbf{T}_{\mathbf{c}}\left[{ }^{\circ} \mathbf{C}\right]$ & $\begin{array}{c}\text { Area h1 } \\
\qquad[\mathbf{J} / \mathbf{g}]\end{array}$ & $\begin{array}{c}\text { Area h2 } \\
{[\mathbf{J} / \mathbf{g}]}\end{array}$ & 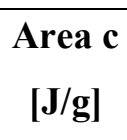 \\
\hline Net1 & -121.9 & -122.2 & -42.3 & -39.1 & -42.1 & -39.7 & -70.0 & 23.9 & 23.6 & -26.7 \\
\hline Net2 & -119.9 & -120.4 & $-45,4$ & & -45.5 & & -76.1 & 19.0 & 19.3 & -21.0 \\
\hline IPN-10 & -121.7 & -121.9 & -42.7 & & -42.7 & & -71.1 & 23.5 & 23.9 & -23.9 \\
\hline IPN-10p & -121.4 & -122.6 & -43.7 & & -43.8 & & -71.4 & 21.3 & 21.4 & -22.9 \\
\hline IPN-50 & -121.2 & -121.1 & -42.2 & & -42.1 & & -71.8 & 23.5 & 23.1 & -24.2 \\
\hline IPN-50p & -119.8 & -119.6 & -42.6 & -40.3 & -42.5 & -40.0 & -70.6 & 23.8 & 24.7 & -25.0 \\
\hline
\end{tabular}
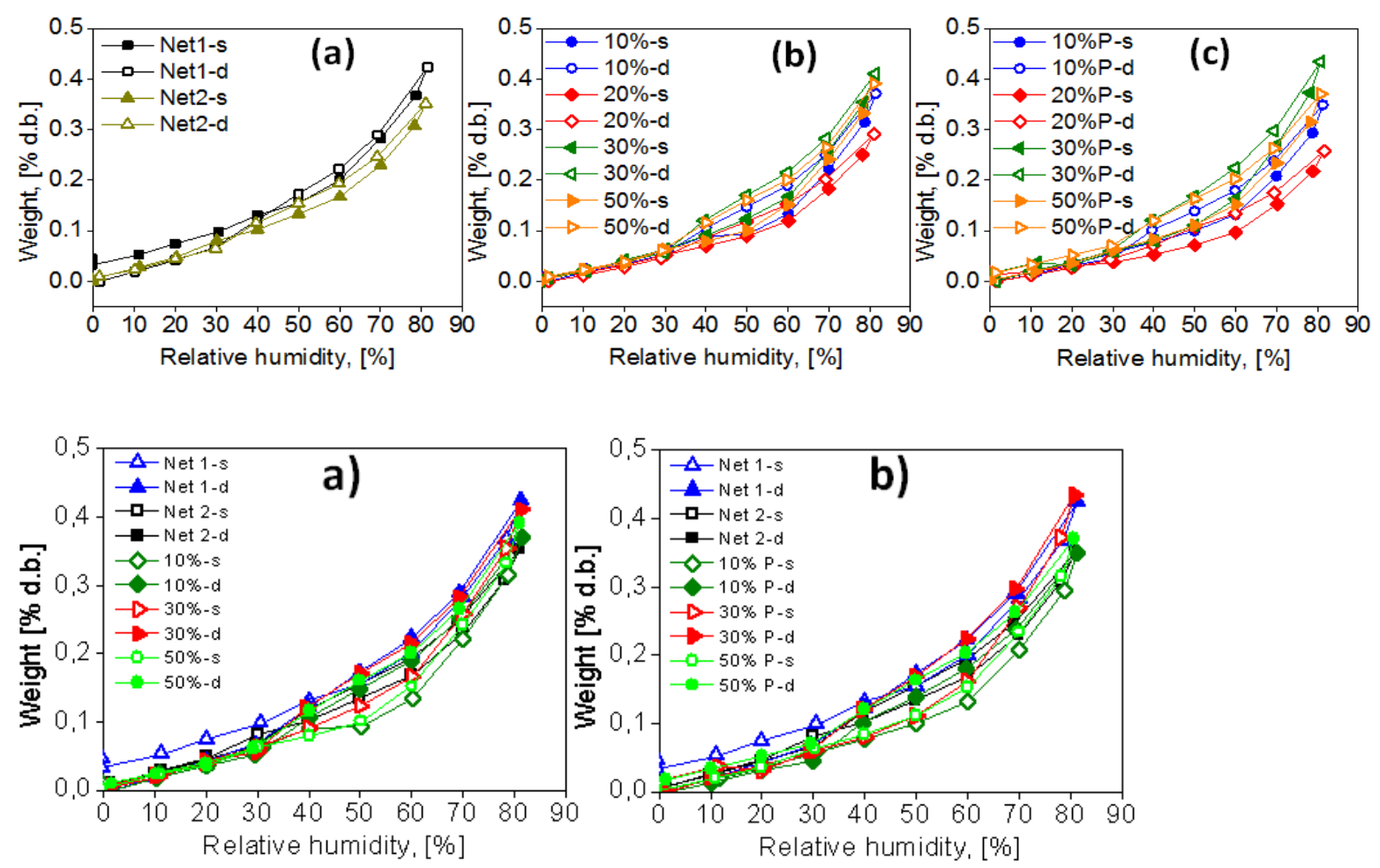

Figure S2. Sorption-desorption isotherms registered in dynamic regime at room temperature for IPNs as compared with references Net1 and Net1. 


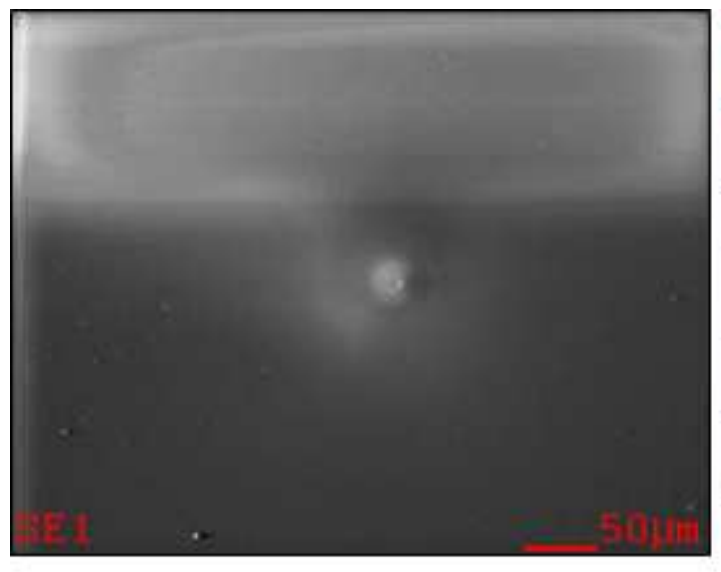

\begin{tabular}{|l|l|l|}
\hline Element & Wt $\%$ & At\% \\
\hline CK & 34.44 & 50.38 \\
\hline OK & 20.02 & 21.98 \\
\hline SiK & 43.97 & 27.50 \\
\hline PtL & 01.58 & 00.14 \\
\hline Matrix & Correction & ZAF \\
\hline \hline
\end{tabular}
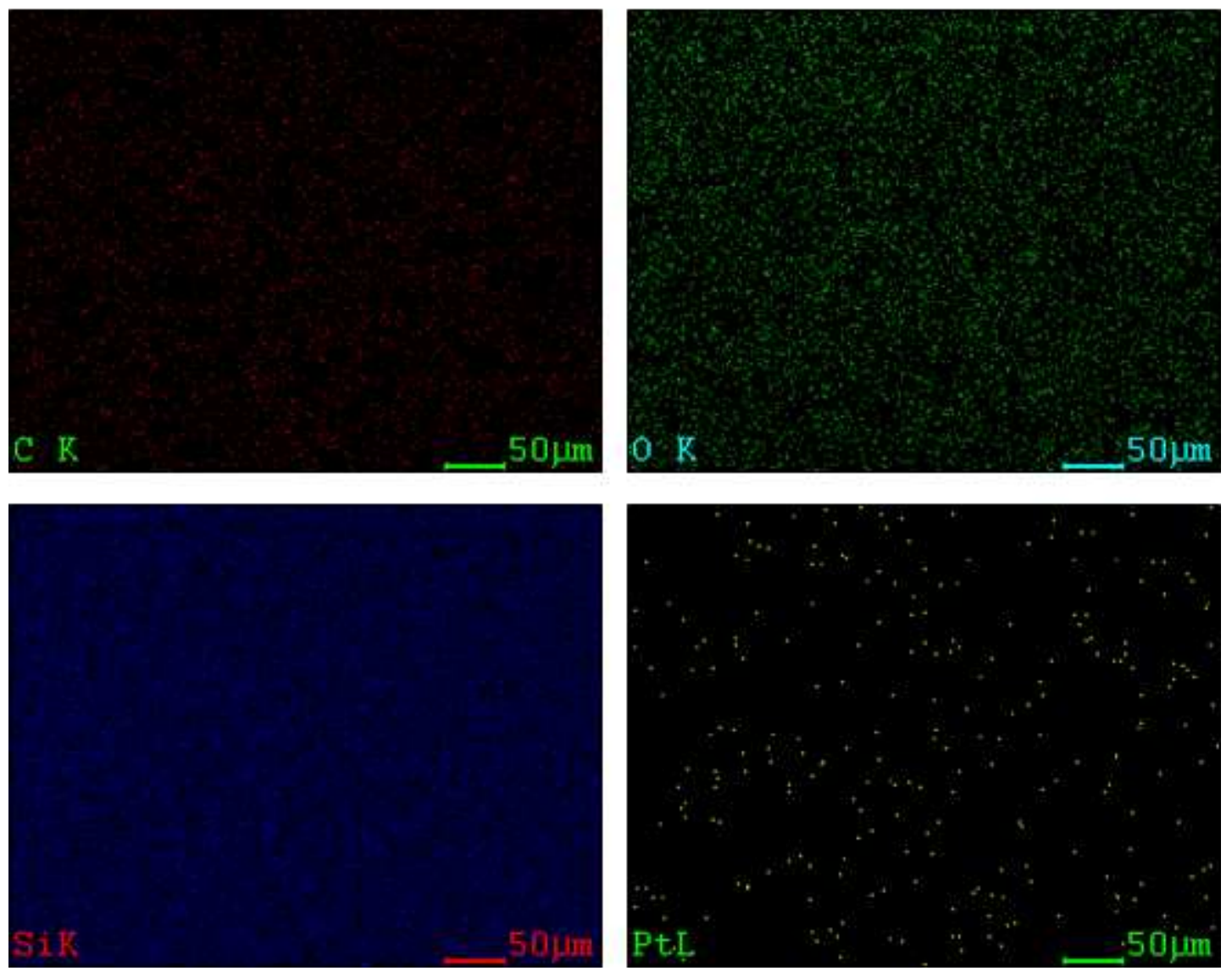

Figure S3. Elemental composition and mapping determined by Energy-dispersive X-ray spectroscopy (EDX) (EDX system available on Scanning Electron Microscope type Quanta 200). 


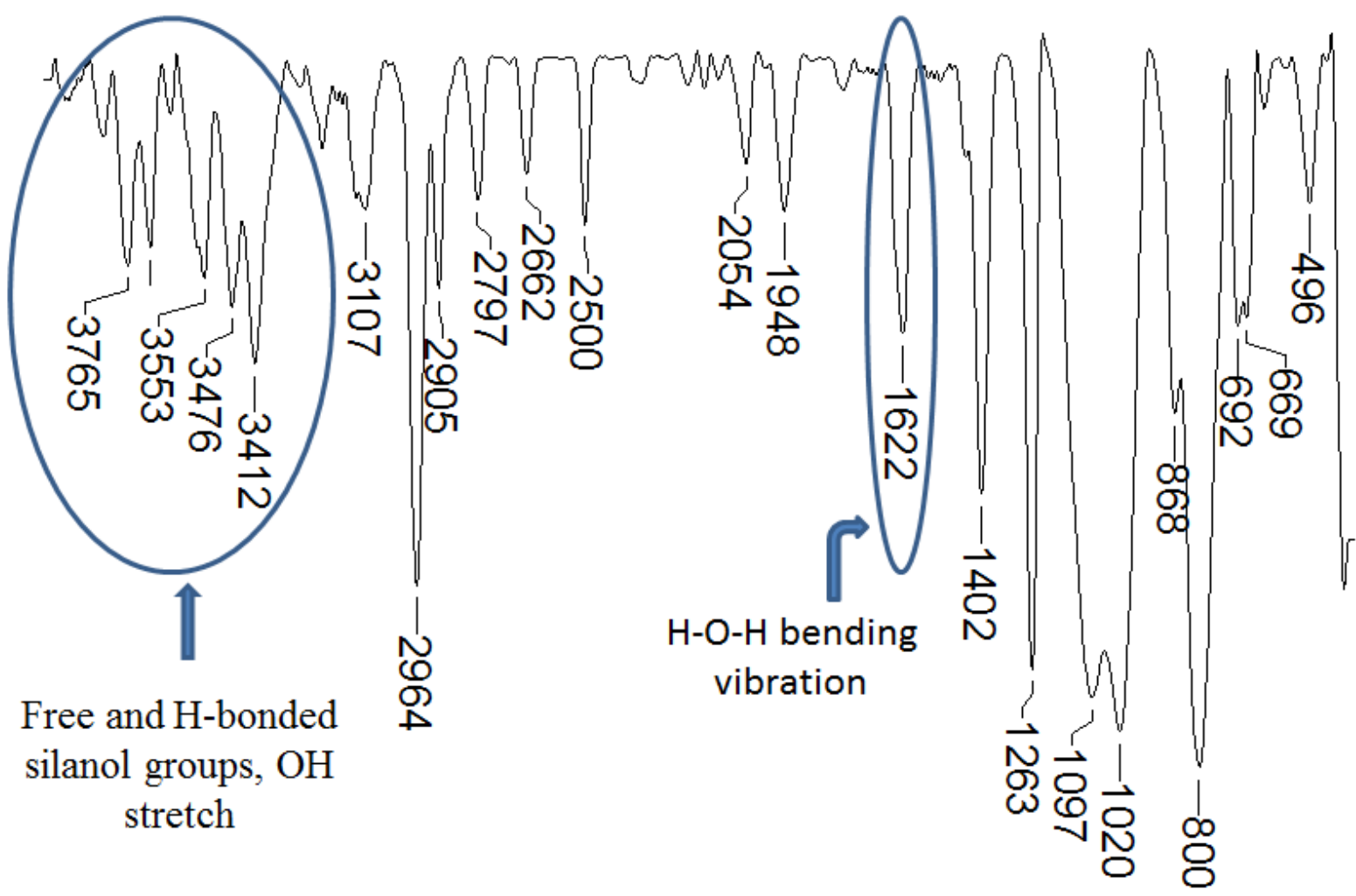

Figure S4. FTIR spectrum of Net2 revealing presence of polar $\mathrm{OH}$ groups ${ }^{1-3}$ (recorded with a Bruker Vertex 70 FTIR spectrometer in transmission mode on crushed sample by grinding in liquid nitrogen and incorporated into $\mathrm{KBr}$ pellets).

Table S2. The ratio between the dielectric loss and dielectric constant, $\tan \delta\left(\tan \delta=\varepsilon^{\prime \prime} / \varepsilon^{\prime}\right)$

\begin{tabular}{lcc}
\hline Sample & $\begin{array}{c}\boldsymbol{\varepsilon}^{\prime \prime} / \boldsymbol{\varepsilon}^{\prime} \\
\text { at } \mathbf{1 ~ H z}\end{array}$ & $\boldsymbol{\varepsilon}^{\prime \prime} / \boldsymbol{\varepsilon}^{\prime} \cdot \mathbf{1 0}$ \\
& 0.19 & 0.64 \\
\hline Net1 & 2.58 & $\mathbf{3 z}$ \\
\hline Net2 & 0.45 & 0.30 \\
\hline IPN-10 & 0.69 & 0.66 \\
\hline IPN-10p & 1.14 & 0.50 \\
\hline IPN-20 & 1.56 & 1.30 \\
\hline IPN-20p & 1.03 & 1.11 \\
\hline IPN-30 & 1.31 & 0.57 \\
\hline IPN-30p & 5.84 & 0.75 \\
\hline IPN-50 & 1.50 & 1.00 \\
\hline IPN-50p & & 0.30 \\
\hline
\end{tabular}




\section{References}

1 Philip J. Launer, Infrared analysis of organosilicon compounds: spectra-structure correlations in Silicone Compounds, Ed. B. Arkles et al Petrarch Systems, 1987

22 Bhaskar J. Saikia, G. Parthasarathy, N. C. Sarmah, Fourier Transform Infrared Spectroscopic Characterization of Dergaon H5 Chondrite: Evidence of Aliphatic Organic Compound, Nature and Science, 2009, 7(5).

3 John Coates, Interpretation of Infrared Spectra, A Practical Approach in Encyclopedia of Analytical Chemistry, John Wiley \& Sons Ltd, Chichester, 2000, 10815-10837. 